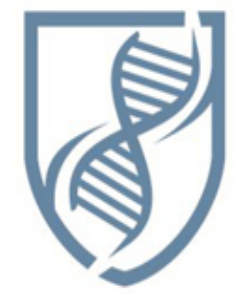

Journal of Bioscience and Applied Research

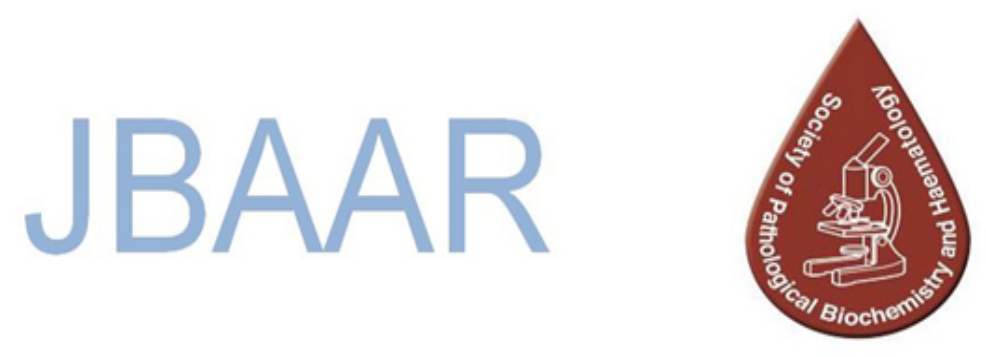

WWW.JBAAR.ORG

\title{
Melatonin counteracts age-related progression of oxidative stress in young Down syndrome patients
}

\author{
Mohamed E. Abdraboh ${ }^{1 *}$, Mohamed A. El missiry ${ }^{1}$, Azza I Othman ${ }^{1}$, \\ Faeza A. El-Dahtory ${ }^{2}$, Nissren Khafaga ${ }^{1}$ \\ ${ }^{1}$ Department of Zoology, Faculty of Science, Mansoura University, Mansoura, Egypt. \\ ${ }^{2}$ Genetic Unit of Children Hospital, 1 Department of Pediatrics and Genetics, Faculty of Medicine, \\ Mansoura University, Mansoura, Egypt. \\ (Corresponding author-e mailmohabdraboh@gmail.com)
}

\begin{abstract}
Melatonin (MLT) is a pineal gland hormone known for its potent antioxidant effect associated with neural protection. The presence of three copies of the SOD gene is considered to be the main cause of oxidative stressdependent neural degeneration and dementia that Down syndrome (DS) patients may suffer from. In this study we aim to assess a possible protective effect of MLTagainst the age-related progression of oxidative stress-induced damage in lymphocytes of DS patients. Lymphocytes from infants with DS were treated with mitomycin $\mathrm{C}$ (an $\mathrm{H}_{2} \mathrm{O}_{2}$ promoter) in order to mimic the oxidative stress status of aged patients in presence and absence of MLT. The data indicated a significant effect of MLT in downregulating the levels of the oxidative radicals $\mathrm{H}_{2} \mathrm{O}_{2}$ and $\mathrm{NO}$ compared to untreated DS patients' lymphocytes. This downregulation was accompanied by a profound effect of MLT in reducing the number of oxidative stress-dependent damaged chromosomes, along with a reduction in cell apoptosis and DNA protection in the p53 dependent pathway. These observations suggest that early administration of exogenous MLT in young DS patients may help in gaining control over growth-related progression of mental retardation, or at least delaying the onset of DS-related pathological complications.

Keywords: Melatonin, Down syndrome, Chromosomes 21, oxidative stress
\end{abstract}

\section{Introduction}

Melatonin (MLT) (N-acetyl-5-methoxytryptamine) is a powerful antioxidant that is mainly secreted from pineal gland and other extra-pineal sources like the retina, gastrointestinal tract, lens, and immune system cells (Acuña-Castroviejo et al., 2014). As a potent antioxidant, MLT ceases cell oxidative stress by 1 ) directly scavenging free radicals, 2) modulating the expression of antioxidant enzymes, and 3) as a counteracting molecule against oxidative stress-induced DNA damage (Geihs et al., 2010).This triple mechanism of action renders melatonin a "super-potent" antioxidant against oxidative stress-induced damage on all relevant levels(García et al., 2014).

MLT behaves like other $\mathrm{H}_{2} \mathrm{O}_{2}$-metabolizing enzymes, such as glutathione peroxidase (GSH-Px) and catalase (CAT), in the removal of this oxidizing agent and reduction of the generation of $\left({ }^{\circ} \mathrm{OH}\right)($ Sliwinski et al., 2007).The byproducts of the interaction of MLT with $\mathrm{H}_{2} \mathrm{O}_{2}$, including N1-acetyl-N2-formyl-5methoxykynuramine (AFMK) (Maharaj et al., 2007)and cyclic 3-hydroxymelatonin, may also function as scavengers of toxic reactants, which illustrates MLT high efficacy in reducing free radical damage in vivo(Bonnefont-Rousselot and Collin, 2010).Furthermore, MLT has an indirect action on oxidative stress by 
downregulating the ROS levels, playing a pivotal role in antioxidant enzymes such as SOD (both MnSOD and CuZnSOD), catalase (CAT), glutathione peroxidase (GPx), glutathione reductase (GRd) and glucose-6-phosphate dehydrogenase (G6PD) (Polimeni et al., 2014).These facts illustrate the protective role that MLT plays in both initial and advanced stages of diseases whose pathogenesis involves damage by oxygen free radicals. Therefore, it is anticipated that MLT may be an appropriate approach to reduce chromosomal damage in DS children in order to control its related pathological features (Reiter et al., 2014).Recent studies illustrate the possible implication of MLT in regulation of DS accompanied pathological features. The diurnal downregulation of MLT endogenous levels is a hallmark of blood samples from DS patients (Uberos et al., 2010). Chronic MLT treatment of Ts65Dn mouse, well known animal model of DS, leads to a control of age-related progression of DS oxidative stress dependent alteration of neurons, synaptic placticity and basal forebrain cholinergic neurons function leading to an enhancement of their memory and spatial learning (Corrales et al., 2013; Corrales et al., 2014).

DS (Trisomy 21) is a worldwide genetic disorder caused by the presence of an extra copy of chromosome 21 (Zhang et al., 2013). DS-related pathological features are a direct result of excessive expression of the chromosome 21-allocated gene for superoxide dismutase (SOD-1). Children with DS are reported to have increased activity of the antioxidant enzyme SOD that can cause oxidative damage to cells by increasing hydrogen peroxide generation levels (Žitňanová et al., 2006).Oxidative stress in certain phases of developmental growth may injure fetal organs and tissues and cause neurodegeneration resulting in dementia and early Alzheimers' disease (AD) onset (Zana et al., 2007).

Chromosome 21 contains several genes that have been implicated in oxidative stress related to neurodegeneration, including $\mathrm{Cu} / \mathrm{Zn}$ superoxide dismutase (SOD1), amyloid precursor protein (APP), ETS-2 transcription factors, Down Syndrome Critical Region 1 (DSCR1) stress-inducible factor, beta-site APP cleaving enzyme (BACE) and S100 (Lott, 2012). Even though, Trisomy of SOD-1 accounts for 95\% of DS cases (Patel et al., 2014). The SOD1 enzyme is involved in many physiological processes including transcription regulation, protein activation, bioenergy output, and cell proliferation (Young and Bennett, 2010).This cytosolic enzyme catalyzes the dismutation of superoxide radicals that are formed during oxidative metabolism to hydrogen peroxide and oxygen. Under normal circumstances, hydrogen peroxide is removed by glutathione peroxidase or catalase. Hydroxyl radicals $\left({ }^{\circ} \mathrm{OH}\right)$ are generated during dismutation of superoxide by SOD (Sulthana et al., 2012). Hydroxyl radicals are highly reactive compounds that can damage neuronal membranes, cellular structures and organelles (Akinci et al., 2010).

An increasing number of studies have shown that oxidative stress occurs in DS pathogenesis and progression due to a deregulation of gene/protein expression associated stimulating the activity of important with the trisomy characteristic of DS (Conti et al., 2007).Increased production of ROS is also accompanied by mitochondrial dysfunction, which occurs in DS cells as early as the embryonic stage(Perluigi and Butterfield, 2011).Although oxidative stress implications in the DS phenotype have been demonstrated(Cenini et al., 2012), a direct cause-and-effect relationship between the accumulation of oxidatively mediated damage and clinical manifestation of DS is not yet strongly established.

This in vitro study aimed to assess the possible effect of MLT as a potent endogenous antioxidant in reducing the progression of DS-accompanied pathological features, which appears mainly as an output of oxidative stress induced chromosomaldamage, using an in vitro model of human lymphocytes in order to mimic the age related progression of DS dependent pathology.

\section{Materials and Methods \\ Patients and samples collections}

The strategy of this study is to in vitro investigate the effect of MLT on diminishing the age-related progression of DS-accompanied syndromes, which appear mainly as a function of oxidative stress-induced chromosomal breakage. Blood samples of fifteen DS patients' and normal children were collected from the presented outpatients to the Genetics Unit of Mansoura University Childrens' hospital. Their ages ranged from neonates to 4 months. This age range was chosen specifically to avoid the endogenous expression of MLT, as the pineal gland starts secreting MLT at 5-6 months after birth (Kennaway et al., 1992; Ardura et al., 2003). Blood samples were collected from the antecubital vein in chilled tubes containing heparin as anticoagulant. The study plan was approved by Mansoura University ethical committee.

\section{Antibodies, Chemicals and Reagents}

RPMI-1640 medium, L- glutamine, penicillin/streptomycin (P/S) and fetal bovine serum (Gibco, USA). Mitomycin C (MMC), Melatonin (SigmaAldrich, CA, USA), Phytohaemaglutinin (PHA-L) pure, Colcemid, Giemsa stain powder (Biochrom AG, Berlin). FITC Conjugated rabbit anti p53, Bax antibodies (Santa Cruz, CA, USA). SOD enzyme activity, total antioxidant capacity and $\mathrm{H}_{2} \mathrm{O}_{2}$, NO generation levels were estimated using colorimetric detection kits (Bio-diagnostic, Giza, Egypt).

\section{Assessment of oxidative stress status in plasma of DS} patients

Half of the collected blood samples were centrifuged at $1500 \mathrm{xg}$ for $10 \mathrm{~min}$ to separate blood cells from plasma. The plasma was then kept frozen at $-80{ }^{\circ} \mathrm{C}$ until further use. Colorimetric estimation of the level of SOD and total antioxidant activities and generation levels of $\mathrm{H}_{2} \mathrm{O}_{2}$ and $\mathrm{NO}$ free radicals in blood plasma of normal (control) and DS patients' children was conducted according to manufacturers' protocol (Biodiagnostics, Giza, Egypt). 
Effect of MLT on oxidative stress status in peripheral blood lymphocytes

Lymphocytes were isolated from two ml freshly drawn, heparin coated Histopaque 1077 (Sigma, Germany) by adding equal volume of Ficoll-Paque to PBS diluted blood samples $(\mathrm{V} / \mathrm{V})$. The samples were centrifuged at $800 \mathrm{gx}$ for $20 \mathrm{~min}$. at room temperature and the interface of lymphocytes was collected using bulb glass pipette. The cells were then washed twice with phosphate-buffered saline (PBS) (pH 7.2). Isolated cells were then cultured in complete RPMI medium (10\%FBS, 1\% P/S) for $72 \mathrm{hr}$ in the presence and absence of $16 \mathrm{mg} / \mathrm{ml}$ of Mitomycin C (MMC), and MMC plus MLT (0.8mg/ml).

MLT protective effect on DS patients' chromosomal breakage

Half $\mathrm{ml}$ of the DS young children patients' lymphocyte-rich plasma was introduced into a sterile 15 $\mathrm{ml}$ culture tube containing $5 \mathrm{ml}$ of complete RPMI culture medium, supplemented with $0.2 \mathrm{ml}(0.048 \mathrm{mg})$ phytohemaglutinin, to initiate mitosis. MMC (16 mg/ml), $\mathrm{H}_{2} \mathrm{O}_{2}$ promotor in order to mimic age-related progression of oxidative stress, was added to the culture medium in presence and absence of different concentrations of MLT $(0.16,0.48 \& 0.8 \mathrm{mg} / \mathrm{ml})$. For chromosomal structure study the cultured cells were incubated at $37{ }^{\circ} \mathrm{C}$ for $72 \mathrm{hrs}$. Afterwards, mixed with colcemide solution $(10 \mu \mathrm{g} / \mathrm{ml})$ for 1.5 hours. After centrifugation at $1000 \mathrm{rpm}$ for $10 \mathrm{~min}$. cell pellets were fixed using freshly prepared Fixative (absolute methanol 3: 1 glacial acetic acid). Two drops of the suspension were placed a part on pre-cleaned and grease-free slidethen dried on $60^{\circ} \mathrm{C}$ hotplate for 2 minutes. The slide was stained for 6 minutes in freshly prepared Giemsa solution (El-Dahtory, 2012).

Comet assay (Single cell gel electrophoresis)

To evaluate MLT protective effect against oxidative stress dependent DNA damage, Cells of MMC untreated, treated and MLT+MMC treated DS patients' lymphocytes were electrically separated using single-cell gel electrophoresis approach as previously described (Nandhakumar et al., 2011). Migrated cells were analyzed on each slide using the Comet Assay II automatic digital analysis system

Flowcytometry

Analysis of cell apoptosis

Lemphocytes were incubated for $24 \mathrm{hr}$ at $37^{\circ} \mathrm{C}$ and $5 \% \mathrm{CO} 2$ in the absence and presence of MMC $(16 \mathrm{mg} / \mathrm{ml})$, and in the presence of MMC with melatonin $(0.8 \mathrm{mg} / \mathrm{ml})$. Subsequently, the cells were collected, washed in PBS and fixed in $70 \%$ ethanol at $4^{\circ} \mathrm{C}$ overnight. Then, the cells were centrifuged at $380 \mathrm{xg}$ for $5 \mathrm{~min}$ at room temperature. The supernatant was removed and the cells re-suspended in PBS and centrifuged again. The supernatant was discarded and the cell pellet was re-suspended in $200 \mu \mathrm{L}$ of PBS. Cells were incubated with propidium iodide for $30 \mathrm{~min}$ at room temperature, then filtered through a $30 \mathrm{~mm}$ pore diameter nylon mesh filter of flow cytometry tube to eliminate nuclear clumps. The cell cycle distribution and percentage of apoptosis was estimated from the resulting figure (FACS can, Becton Dickinson, Germany).
Determination of Bax and p53 expression in lymphocytes

A cell suspension of DS patients' lymphocytes in presence and absence of MMC and MMC plus MLT $\left(1 \mathrm{X} 10^{5}\right.$ cell) was prepared with PBS/BSA buffer (phosphate buffer saline and 1\% bovine serum albumin). Bax and/or p53 FITC conjugated antibodies were mixed well with cell suspension and incubated for $30 \mathrm{~min}$ at room temperature. Afterwards, Cells were washed with $2 \mathrm{ml}$ PBA/BSA and centrifuged at 400rpm for $5 \mathrm{~min}$, and then the supernatant was discarded. Finally, cells were suspended in $0.2 \mathrm{ml} 0.5 \%$ paraformaldehyde in PBS/BSA and analyzed via flow cytometry.

\section{Statistical Analysis}

Differences between mean values were assessed for statistical significance using a two-tailed Students' ttest (GraphPad Prism 4.0 software, La Jolla, CA). P values $<0.05$ were considered statistically significant.

\section{Results}

The prevalence of antioxidant enzymes and ROS in plasma of DS patients

Blood samples of the DS patients' and normal childrens' as controls were collected and tested for the prevalence of free radicals such as $\mathrm{H}_{2} \mathrm{O}_{2}$, NO, activity of SOD enzyme and total antioxidant capacity (TAC) (Fig. 1). The data showed significant upregulation in the activity of SOD and TAC in DS patients in comparison to controls. This elevation was correlated with a spontaneous increase in $\mathrm{H}_{2} \mathrm{O}_{2}$ and $\mathrm{NO}$ generation levels.

MLT counteract the oxidative stress dependent chromosomal damage in DS patients' lymphocytes

In order to mimic the growth time dependent increase at oxidative stress and their effects on chromosomal destruction and degeneration of cells in growing DS patients',Harvested lymphocytes of the expected patients were first tested for the presence of 21 trisomy using karyotyping approach (Fig.2A). Afterwards, an in vitro model of DS young children patients' lymphocytes was developed by culturing the cells in presence of MMC which is a potent $\mathrm{H}_{2} \mathrm{O}_{2}$ generation promoter. MMC $(16 \mathrm{mg} / \mathrm{ml})$ treated cells were cultured in absence (+ ve control) and presence of different concentrations of $\operatorname{MLT}(0.16,0.48,0.8 \mathrm{mg} / \mathrm{ml})$ in order to determine the most effective dose for chromosomal protection. The resulting data showed that MMC induced a significant increase in the number of damaged chromosomes in lymphocytes of DS patients. The concomitant treatment of lymphocytes with 0.48 , $0.8 \mathrm{mg} / \mathrm{ml}$ of MLT resulted in a highly significant reduction in the number of $\mathrm{H}_{2} \mathrm{O}_{2}$-induced damaged chromosomes compared to the number of damaged chromosomes in MMC only treated lymphocytes (Fig.2 A, B).

Effect of MLT on activity of SOD and levels of the related ROS in DS patients' lymphocytes

In order to elucidate the mechanism of action through which MLT exerts its cytoprotective effect against oxidative stress-dependent chromosomal damage, the collected DS patients' lymphocytes were cultured in the 
absence and presence of MMC and MMC plus MLT(0.8 $\mathrm{mg} / \mathrm{ml}$ ) for 72 hrs. The MLT cytoprotective effect was assessed by determining the cellular levels of $\mathrm{H}_{2} \mathrm{O}_{2}$, NO and activity of SOD (Fig 3). The data showed a nonsignificant decrease in activity of SOD in the MLT plus MMC treated group in comparison to the MMC only treated group. Meanwhile, a significant decrease in generation of both $\mathrm{H}_{2} \mathrm{O}_{2}$ and $\mathrm{NO}$ free radicals was recorded in MLT plus MMC treated lymphocytes in comparison to MMC only treated group.

Effect of MLT on DNA damage and cell apoptosis

Detection of oxidative stress-dependent DNA damage in DS patients' lymphocytes

In order to illustrate the possible role of MLT treatment in eradicating the destructive effect of DSrelated oxidative stress on DNA content, the studied groups' lymphocytes were cultured in the absence and presence of MMC and MMC plus MLT for $24 \mathrm{hr}$, then tested for percentage of damaged DNA using a comet assay approach. The percentage of DNA damage was determined by the percentage of DNA content and tail length of the migrated cells. The presented data revealed a significant decrease in tail length of fragmented DNA in MMC plus MLT in comparison to MMC only treated lymphocytes (Fig. 4 )

Effect of MLT in diminishing of cell apoptosis

As the process of oxidative stress-dependent chromosomal breakage always results in apoptosis of the affected cells, it was of interest to test the effect of MLT on the apoptotic process in MMC-treated DS patients' lymphocytes. The presented data showed a significant increase in a fraction of apoptotic cells in MMC treated lymphocytes compared with MMC untreated cells. Meanwhile, MLT treated cells showed significant protective effect against MMC-dependent cell apoptosis by downregulating the number of apoptotic cells to a level much closer to MMC untreated DS cells. These data showed the potent antioxidant effect of MLT in protecting DS patients from oxidative stress-induced cell damage which is a hallmark of later DS-related pathological changes (Fig 5A).

Determination of p53 in DS patients' lymphocytes

In order to elucidate the mechanism of action underlying the MLT significant cytoprotective effect in conserving DS patients' lymphocytes from MMC-induced DNA damage, we assessed the expression level of the DNA keeper and pro-apoptotic protein p53 at (A) DS untreated cells, (B) MLT only treated cells, (C) MMC only treated cells and (D) MMC plus MLT treated cells using flow cytometry. The presented data showed a highly significant effect of MLT in ceasing the oxidative stressdependent expression of p53 in both MMC treated and untreated DS patients' lymphocytes (Fig 5 B).

\section{Effect of MLT on Bax expression}

In order to confirm these results, we assessed the percentage of expression of the pro-apoptotic protein Bax in lymphocytes of DS patients in the presence and absence of MMC and/or MLT. The presented data showed a highly significant downregulation in the expression of Bax in MMC plus MLT treated cells in comparison to MMC only treated cells. These results support the role of MLT as potent antioxidant in eradicating the oxidative stressdependent induction of cell apoptosis in DS patients' lymphocytes (Fig 5 C).

Fig. 1
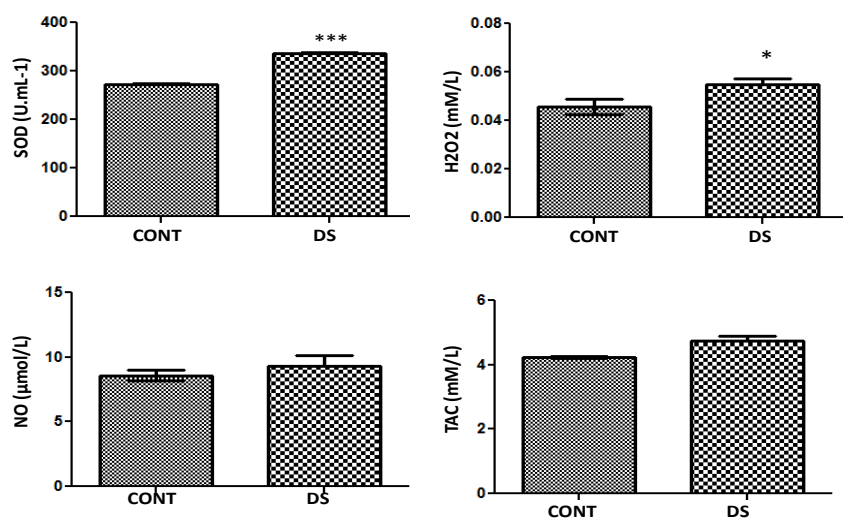

Figure (1): Prevalence of oxidative stress status in patients of D.S blood plasma. The data revealed a significant increase at SOD activity, $\mathrm{H}_{2} \mathrm{O}_{2}$ generation levels and insignificant increase at No and TAC has been recorded in plasma of DS young children patients' as compared to their levels in normal children plasma. The significance level has been denoted as $* * *(\mathrm{P}<0.0001)$ 
Fig.2

A.
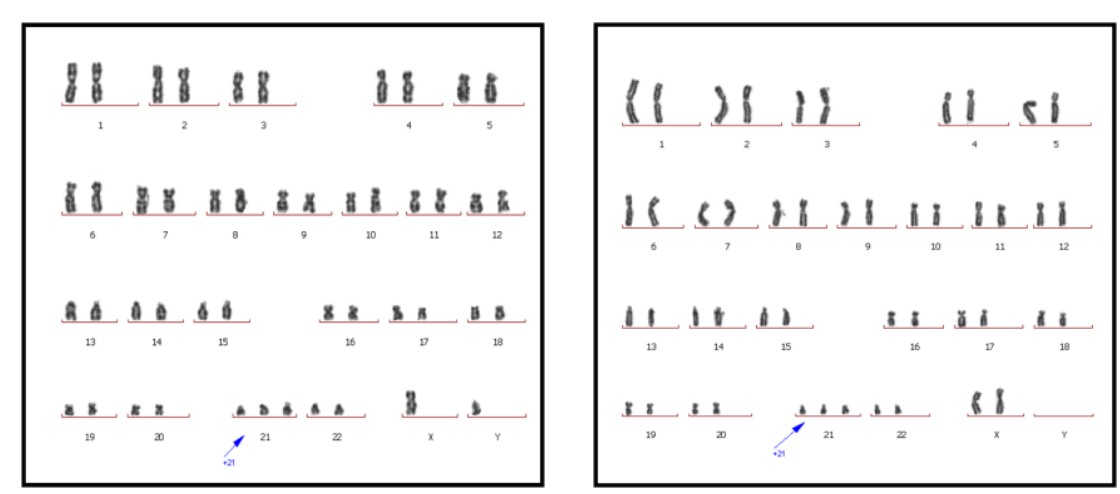

B.

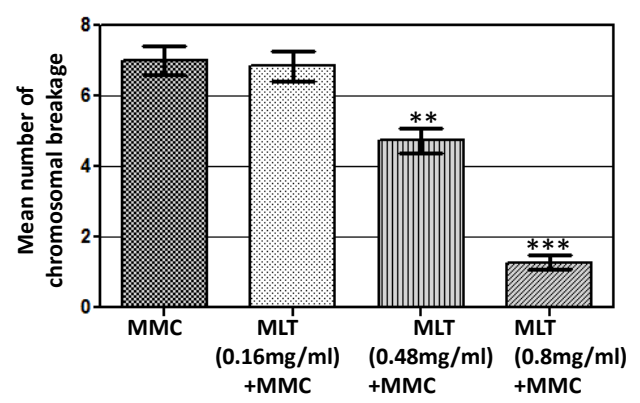

Figure 2(A\&B): (A) Karyotyping of males and females young children DS patients' indicated the presence of Chr 21 trisomy. (Left panel) Male DS patients'(Right panel) Female DS patients' (B) Cyto-protective effect of MLT against the MMC dependant chromosomal damage at Down syndrome patient's lymphocytes. The data showed a significant dose dependent cyto-protective effect of MLT on over countering the destructive effect of MMC on chromosomal structure, mainly at a dose of $(0.8 \mathrm{mg} / \mathrm{ml})$ of MLT . The data were presented as Mean + SEM and significance was denoted as ( $\left.\mathrm{p}<0.0001^{* * *}\right)$.

Fig 3
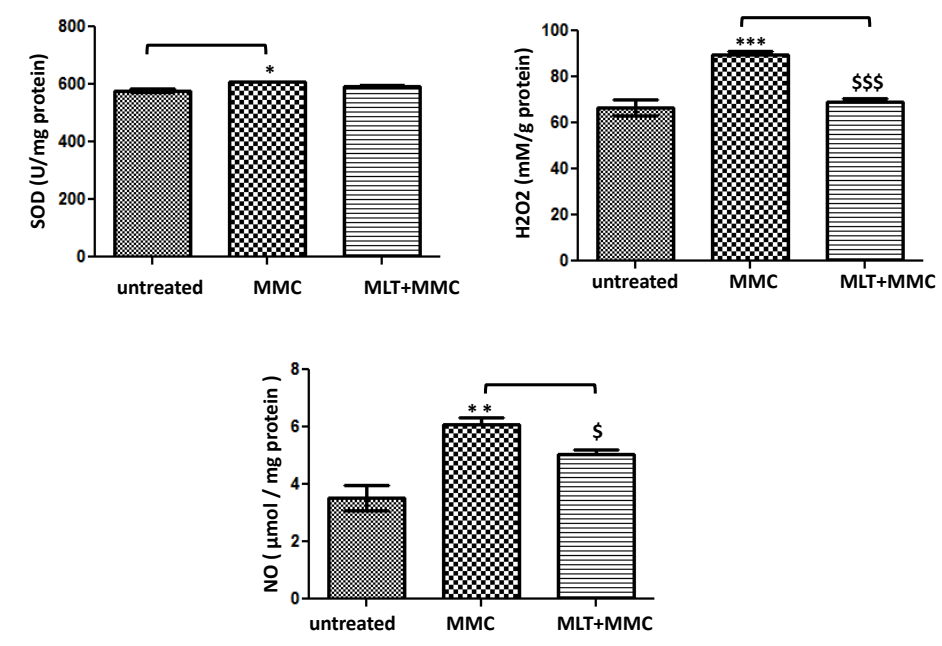

Figure (3): Antioxidant activity of MLT against MMC dependent oxidation. DS patients' lymphocytes were cultured in the absence, presence of MMC and MMC plus MLT. The presented data showed a significant MMC dependent stimulation of cellular levels of $\mathrm{H}_{2} \mathrm{O}_{2}$, NO generation and SOD activation which is over-countered by MLT application significantly for $\mathrm{H}_{2} \mathrm{O}_{2}$, NO and insignificantly for SOD. Significance was denoted as ${ }^{* * *}$, \$\$ $(\mathrm{P}<0.0001)$ as compared with untreated and MMC, recepectively. 
Fig. 4
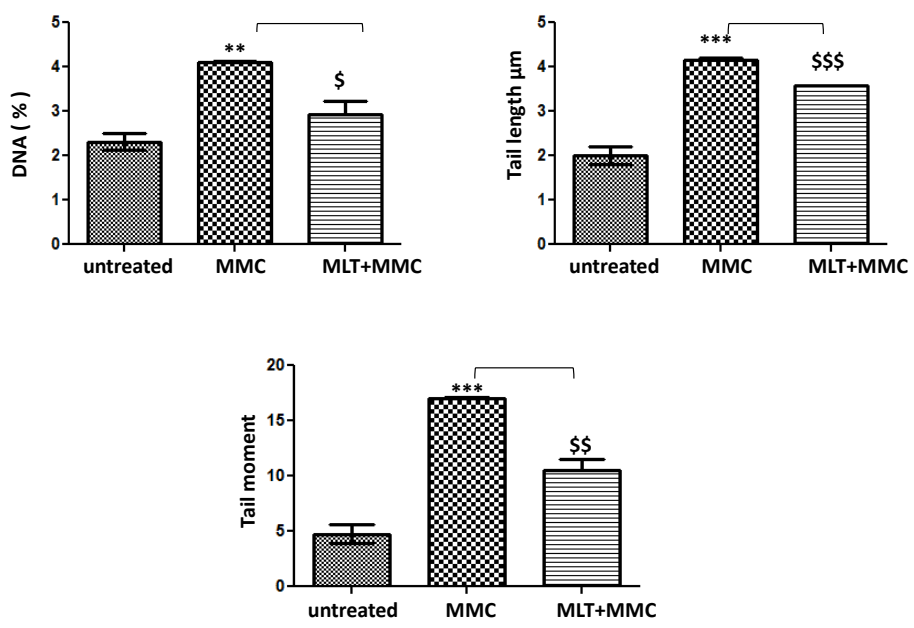

Fig 4 (A\&B): A. photomicrographs of comet assay of lymphocyte cells of DS patients', in presence and absence of MLT and MMC. (A) Untreated DS cells, (B) MMC treated cells and (C) MMC+ MLT treated cells. White stars symbol to damaged DNA. (B) Histograms showed the change at percentage of DNA concentration, tail length and tail moment of lymphocyte cells. The presented data revealed a significant effect of MLT on downregulating the number of MMC oxidative damage of DS patients' lymphocytes. The significance was denoted as ${ }^{* * *}, \$ \$ \$(P<0.0001)$ as compared with untreated and MMC treated, respectively.
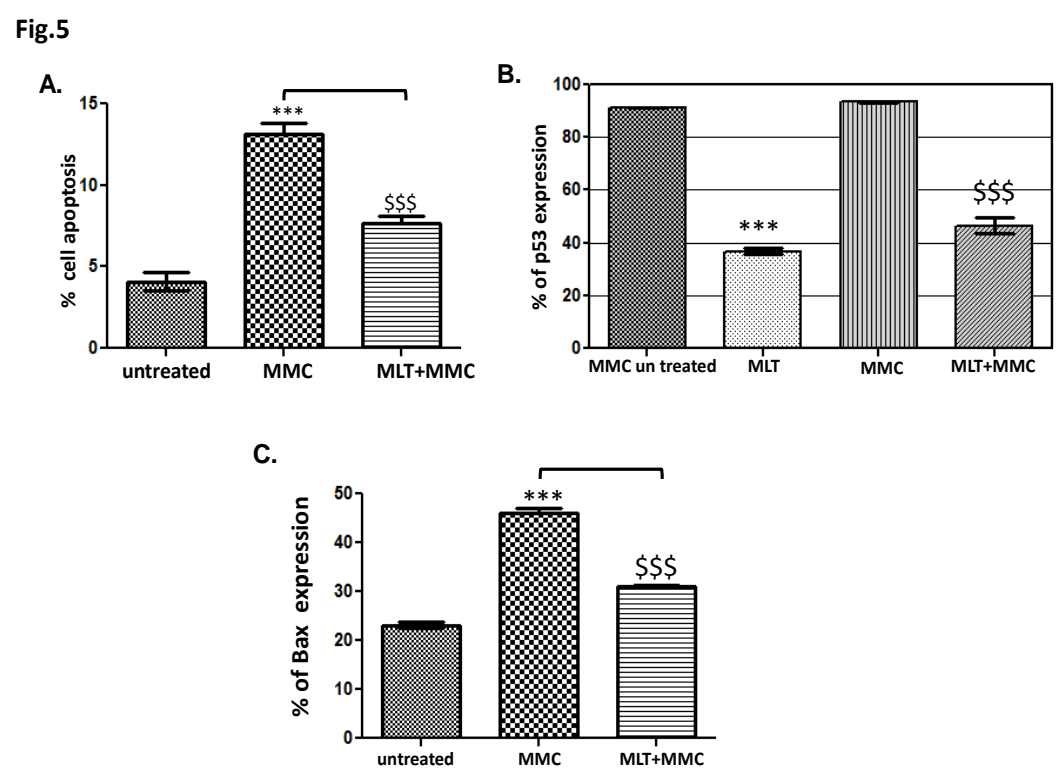

Figure 5: Molecular studies of MLT cyto-protection against oxidative stress induced apoptosis. (A) MLT significantly downregulated MMC induced apoprosis. (B) The expression of P53 significantly reduced in MLT treated lymphocytes as compared with MMC treated and untreated DS patients' lymphocytes. (C) The expression of pro-apoptotic Bax significantly decreased in MMC+MLT group compared to MMC group. The significance was denoted as ${ }^{* * *}, \$ \$ \$(P<0.0001)$ 


\section{Discussion}

Children with DS have increased vulnerability to oxidative stress, caused mainly by the overexpression of the antioxidant enzyme SOD as a result of an extra copy of the SOD1 gene on chromosome 21. The triplication of chromosome 21 (Trisomy 21) accounts for approximately 95\% of DS cases (Créau, 2012). The upregulation of SOD expression is accompanied by a cellular accumulation of $\mathrm{H}_{2} \mathrm{O}_{2}$. In addition, the imbalance between the activity of essential antioxidant enzymes such as SOD, CAT and GPX leads to a buildup of $\mathrm{H}_{2} \mathrm{O}_{2}$ in affected tissues with later oxidative stress development (Aitken and Roman, 2008; Wang et al., 2013). All DS tissues display an altered SOD1/GPx activity ratio, and SOD was found at levels approximately $50 \%$ higher than normal in a variety of DS cells and tissues(Perluigi and Butterfield, 2011). Antioxidant enzyme analysis showed significant increases in the SOD, CAT and glutathione reductase activities in DS subjects (Zana et al., 2007). Recently, Garlet et al. (2013) assessed the activity of antioxidant enzymes in children and teenagers with DS. The data showed a significant increase in the activity of SOD, CAT and GR, while GST activity was significantly decreased. Meanwhile, a non-significant change in GPx activity was detected (Garlet et al., 2013).

Gulesserian et al stated that the expression of catalase is unaltered in the fetal DS brain. Meanwhile, SOD-1 activity rather than expression was elevated (Gulesserian et al., 2001). One of the leading theories on the pathogenesis and complications associated with DS is that ROS has an early role in DNA damage and cell death. Therefore, the therapeutic use of antioxidants to reduce the incidence and severity of disease seems promising (Sulthana et al., 2012). Supplementation of exogenous antioxidants could play an important role in preventing, treating or at least delaying the progression of DS complications, particularly compensating for the decreased level of endogenous antioxidants. Moreover, the manipulation of endogenous cellular defense mechanisms via endogenous antioxidants may comprise an innovative approach to therapeutics, e.g., neuroprotective intervention in diseases causing tissue damage(Srinivasan et al., 2005; Pandi-Perumal et al., 2013).

In this study we aimed to evaluate the effect of MLT as a powerful well known endogenous antioxidant on the activity level of SOD enzyme as a main factor in DS-related pathology. In addition, we were interested to determine the impact of MLT treatment on chromosomal stability, cell death and DNA damage, all of which play a pivotal role in the development of DS-related diseases such as dementia and leukemia (Nižetić and Groet, 2012).

Donated blood samples were tested for the presence of trisomy 21 (data not shown). Afterwards, they were tested for the activity of SOD enzyme and total antioxidant capacity (TAC) in the plasma of donated samples. Generation levels of main free radicals involved in oxidative stress development such as $\mathrm{H}_{2} \mathrm{O}_{2}$ and NO were also assessed. The resulting data showed a significant increase in SOD enzyme activity and a non-significant increase in TAC (Fig. 1). These results are in line with what has been established in most cases of DS, except for the TAC which has been found to be upregulated in urine and saliva of DS patients (Campos et al., 2010; Subramaniam et al., 2014).

The colorimetric analysis of $\mathrm{H}_{2} \mathrm{O}_{2}$ and NO showed a significant increase in $\mathrm{H}_{2} \mathrm{O}_{2}$ buildup and a non-significant increase in NO generation levels (Fig 1). The significant upregulation in $\mathrm{H}_{2} \mathrm{O}_{2}$ generation levels was expected due to the increased activity of SOD (Poeggeler et al., 2002). A recent study stated that NO generation levels are mainly increased in elderly DS patients, which has been correlated with the development of clinical dementia and Alzheimer's disease (Coppus et al., 2010).

In order to assess the effect MLT on counteractingage-related oxidative stress-dependent chromosomal instability, donated lymphocytes were cultured in the presence of MMC (a well-known $\mathrm{H}_{2} \mathrm{O}_{2}$ generation promoter to induce chromosomal damage) in addition to serial concentrations of MLT. The resulting data showed a highly significant effect of MLT on decreasing the number of damaged chromosomes via eradicating MMC destructive action. The determined effective dose of MLT $(0.8 \mathrm{mg} / \mathrm{ml})$ revealed a highly significant effect on demolishing $\mathrm{H}_{2} \mathrm{O}_{2}$-dependent oxidative stress by downregulating the number of damaged chromosomes in comparison to MMC only treated cells (Fig.2). The antioxidant effect of MLT in protecting chromosomal structure has been covered by several studies. De Salvia et al. presented that MLT promotes a reduction in the number of abnormal chromosomes by downregulating the number of $\mathrm{H}_{2} \mathrm{O}_{2}$ and cyclophosphamide-induced $\mathrm{CHO}$ cells (Ferreira et al., 2013). In a similar study, the ability of MLT to cease oxidative stress-related damage in human and rat chromosomes against gamma irradiation was illustrated (Badr et al., 1999; Assayed and El-Aty, 2009).

Furthermore, we were concerned with assessing the effect of MLT treatment on the activity of the SOD enzyme as well as on the generation levels of both $\mathrm{H}_{2} \mathrm{O}_{2}$ and NO in MMC treated DS patients' lymphocytes. The presented data revealed a significant effect of MLT on downregulating the levels of $\mathrm{H}_{2} \mathrm{O}_{2}$ and $\mathrm{NO}$ in MLT plus MMC treated cells (Fig 3). Interestingly, the data showed a non-significant decrease in SOD activity upon MLT treatment comparable to MMC only treated lymphocytes (Fig. 3). A literature survey showed a potential selective mode of action of MLT on SOD enzyme activity. In a 
study of hypokinesis (where ROS generation increased), MLT treatment caused a slight increase in CuZn-SOD activity after 30 days of MLT supplementation (Mrowicka et al., 2009). In contrast, a study of the effect of MLT on lipid peroxidation and antioxidant enzymes in a hyperthyroidism rat model showed a significant effect of MLT in downregulating the increased level of SOD along with GSH generation levels (Baydas and Meral, 2005).

Moreover, in a recent study of Alzheimer's disease (AD), MLT showed a significant effect in impairing NADPH oxidase activation and assembly in the membrane of microglial cells in AD brain (Zhou et al., 2008). NADPH oxidase is known to be the main enzyme responsible for generation of super oxide anions $\left(\mathrm{O}_{2}{ }^{\prime}\right)$ which is the SOD enzyme substrate for $\mathrm{H}_{2} \mathrm{O}_{2}$ synthesis (Paravicini and Touyz, 2008). As an inducible enzyme, the prolonged absence of the SOD enzyme substrate $\left(\mathrm{O}_{2}\right)$ would lead instantly to a downregulation in its activity, which, in addition to its potent free radical scavenging ability, leadsto a significant decrease in $\mathrm{H}_{2} \mathrm{O}_{2}$ cellular levels (Fig. 3a). Such a mechanism of action, in addition to the short term of MLT treatment in our study (72hr), may account for the MLT-related non-significant reduction in SOD activity in comparison to MMC only treated cells.

In spite of the non-significant decrease at SOD activity, MLT acts directly as a potent free radical scavenger(Sofic et al., 2005; Polimeni et al., 2014) and significantly demolishes the lymphocyte cellular levels of both $\mathrm{H}_{2} \mathrm{O}_{2}$ and $\mathrm{NO}$ (Fig 3).

Afterwards, we were interested in identifying one of the molecular mechanisms though which MLT protects chromosome structure and increases its stability by determining the effect of MLT on cell apoptosis and DNA content of the treated cells using flowcytometry and comet assay approaches.

Our comet assay studies revealed a significant effect of MLT in ceasing the $\mathrm{H}_{2} \mathrm{O}_{2}$-dependent increase in tail length and percentage of damaged DNA of migrated cells (Fig. 4). The protective role of MLT against DNA damage in the present study is in agreement with previous findings. Several studies have suggested that MLT may protect DNA against free radical damage by scavenging ROS including ${ }^{-} \mathrm{OH}$ and $\mathrm{H}_{2} \mathrm{O}_{2}$ (Erenberk et al., 2014), stimulating DNA repair capacity (Liu et al., 2013), and enhancing the expression of DNA repairing Xpf mRNA (Ferreira et al., 2013).

These findings were tested by determining the expression level of the DNA keeper protein p53 in MMC and MMC plus MLT treated cells. The data showed a significant effect of MLT in demolishing the expression of p53 in both MMC treated and untreated DS patients' lymphocytes. The remarkable impact of MLT in excising ROS generation may explain its inhibitory effect on p53 expression. These results agree with and may support the findings of Zhang et al., who stated that the upregulation of p53 expression in DS patients is a main consequence of DNA oxidative damage, which in turn upregulates the expression of pro-apoptotic protein caspase 9 through miR-1246/DYRK1A signaling pathway (Zhang et al., activity after 10 days of treatment, with a later significant rise 2011). Overactivation of p53 in DS neuroglial cells may explain the increased susceptibility of DS brain cells to apoptosis (Liao et al., 2012). Furthermore, the effect of MLT on cell apoptosis was tested using flow cytometry approach. MLT showed a highly significant effect on abrogating apoptotic cells in MMC plus MLT treated DS patient lymphocytes (Fig 5 A,B). In order to confirm this result, we estimated the P53 signaling dependent expression of the pro-apoptotic protein Bax in MMC only and MMC plus MLT treated lymphocytes. The results revealed a significant effect of MLT in downregulating the expression of Bax in MLT treated cells (Fig. 5C). A recent study concerning the role of MLT in a rat model of chronic intermittent hypoxia indicated MLTs' crucial role in inhibiting hypoxia-related hippocampal neuron apoptosis via scavenging of free radicals and targeting the Bax/BCL2 apoptotic pathway (Tan et al., 2013).

This in vitro study proposed MLT as a potential drug for controlling age-dependent progression of DSrelated pathological features via scavenging the accumulated cellular free radicals. The MLT dependent absence of ROS and oxidative stress leads to an inhibition of DNA damage and cell apoptosis via targeting the ROS/p53/miR1246/DYRK1A/Caspase 9 signaling cascade and $\mathrm{Bax} / \mathrm{Bcl}-2$ apoptotic pathway. These results may provide the impetus for further research leading to the use of pineal gland hormone in protecting the genome structure of DS patients' tissues.

\section{References}

Acuña-Castroviejo, D.; Escames, G.; Venegas, C.; Díaz-Casado, M. E.; Lima-Cabello, E.; López, L. C.; Rosales-Corral, S.; Tan, D.-X. and Reiter, R. J. (2014). 'Extrapineal melatonin: sources, regulation, and potential functions', Cellular and Molecular Life Sciences, 71(16): 2997-3025.

Aitken, R. J. and Roman, S. D. (2008). 'Antioxidant systems and oxidative stress in the testes', Oxidative medicine and cellular longevity, 1(1): 15-24.

Akinci, O.; Mihci, E.; Tacoy, S.; Kardelen, F.; Keser, I. and Aslan, M. (2010). 'Neutrophil oxidative metabolism in Down syndrome patients with congenital heart defects', Environmental and molecular mutagenesis, 51(1): 57-63.

Ardura, J.; Gutierrez, R.; Andres, J. and Agapito, T. (2003). 'Emergence and evolution of the circadian rhythm of melatonin in children', Hormone Research in Paediatrics, 59(2): 66-72.

Assayed, M. E. and El-Aty, A. A. (2009). 'Protection of rat chromosomes by melatonin against gamma radiation-induced damage', Mutation Research/Genetic Toxicology and Environmental Mutagenesis, 677(1): 14-20.

Badr, F.; El Habit, O. and Harraz, M. (1999). 'Radioprotective effect of melatonin assessed by measuring chromosomal damage in mitotic and meiotic 
cells', Mutation Research/Genetic Toxicology and Environmental Mutagenesis, 444(2): 367-372.

Baydas, B. and Meral, I. (2005). 'Effects of Melatonin on lipid peroxidation and anti-oxidant enzyme activity in rats with experimentally induced Hyperthyroidism', Clinical and experimental pharmacology and physiology, 32(7): 541-544.

Bonnefont-Rousselot, D. and Collin, F. (2010). 'Melatonin: action as antioxidant and potential applications in human disease and aging', Toxicology, 278(1): 55-67.

Campos, C.; Guzmán, R.; López-Fernández, E. and Casado, Á. (2010). 'Urinary uric acid and antioxidant capacity in children and adults with Down syndrome', Clinical biochemistry, 43(3),:. 228-233.

Cenini, G.; Dowling, A. L.; Beckett, T. L.; Barone, E.; Mancuso, C.; Murphy, M. P.; LeVine, H.; Lott, I. T.; Schmitt, F. A. and Butterfield, D. A. (2012). 'Association between frontal cortex oxidative damage and beta-amyloid as a function of age in Down syndrome', Biochimica et Biophysica Acta (BBA)-Molecular Basis of Disease, 1822(2): 130-138.

Conti, A.; Fabbrini, F.; D'Agostino, P.; Negri, R.; Greco, D.; Genesio, R.; D'Armiento, M.; Olla, C.; Paladini, D. and Zannini, M. (2007). 'Altered expression of mitochondrial and extracellular matrix genes in the heart of human fetuses with chromosome 21 trisomy', Bmc Genomics, 8(1): 1-15.

Coppus, A.; Fekkes, D.; Verhoeven, W.; Tuinier, S. and van Duijn, C. (2010). 'Plasma levels of nitric oxide related amino acids in demented subjects with Down syndrome are related to neopterin concentrations', Amino acids, 38(3): 923-928.

Corrales, A.; Martínez, P.; García, S.; Vidal, V.; García, E.; Flórez, J.; Sanchez Barceló, E. J.; Martínez Cué, C. and Rueda, N. (2013). 'Long-term oral administration of melatonin improves spatial learning and memory and protects against cholinergic degeneration in middle-aged Ts65Dn mice, a model of Down syndrome', Journal of pineal research, 54(3): 346-358.

Corrales, A.; Vidal, R.; García, S.; Vidal, V.; Martínez, P.; García, E.; Flórez, J.; Sanchez Barceló, E. J.; Martínez Cué, C. and Rueda, N. (2014). 'Chronic melatonin treatment rescues electrophysiological and neuromorphological deficits in a mouse model of Down syndrome', Journal of pineal research, 56(1): 51-61.

Créau, N. (2012). 'Molecular and cellular alterations in Down syndrome: toward the identification of targets for therapeutics', Neural plasticity, 2012:1-12.

El-Dahtory, F. (2012). 'Chromosomal abnormalities and hormonal disorders of primary amenorrhea patients in Egypt', Indian journal of human genetics, 18(2): 183-186.

El-Sayyad, H.; El-Sherbiny, M.; Sobh, M.; AbouEl-Naga, A.; Ibrahim, M. and Mousa, S. (2011). 'Protective effects of Morus alba leaves extract on ocular functions of pups from diabetic and hypercholesterolemic mother rats', Int J Biol Sci, 7(6): 715-728.

Erenberk, U.; Dundaroz, R.; Gok, O.; Uysal, O.; Agus, S.; Yuksel, A.; Yilmaz, B. and Kilic, U. (2014).
'Melatonin attenuates phenytoin sodium-induced DNA damage', Drug and chemical toxicology, 37(2): 233-239.

Ferreira, S.; Peliciari-Garcia, R.; Takahashi-Hyodo, S.; Rodrigues, A.; Amaral, F.; Berra, C.; Bordin, S.; Curi, R. and Cipolla-Neto, J. (2013). 'Effects of melatonin on DNA damage induced by cyclophosphamide in rats', Brazilian Journal of Medical and Biological Research, 46(3): 278-286.

García, J. J.; López-Pingarrón, L.; Almeida-Souza, P.; Tres, A.; Escudero, P.; García-Gil, F. A.; Tan, D. X.; Reiter, R. J.; Ramírez, J. M. and Bernal-Pérez, M. (2014). 'Protective effects of melatonin in reducing oxidative stress and in preserving the fluidity of biological membranes: a review', Journal of Pineal Research, 56(3): 225-237.

Garlet, T. R.; Parisotto, E. B.; de Medeiros, G. d. S.; Pereira, L. C. R.; Dalmarco, E. M.; Dalmarco, J. B. and Wilhelm Filho, D. (2013). 'Systemic oxidative stress in children and teenagers with Down syndrome', Life sciences, 93(16): 558-563.

Geihs, M. A.; Vargas, M. A.; Maciel, F. E.; Caldas, S. S.; Cruz, B. P.; Primel, E. G.; Monserrat, J. M. and Nery, L. E. M. (2010). 'Effect of melatonin in the antioxidant defense system in the locomotor muscles of the estuarine crab Neohelice granulata (Decapoda, Brachyura)', General and comparative endocrinology, 166(1): 72-82.

Gulesserian, T.; Engidawork, E.; Fountoulakis, M. and Lubec, G.(ed.) (2001).'Antioxidant proteins in fetal brain: superoxide dismutase-1 (SOD-1) protein is not overexpressed in fetal Down syndrome. Springer-Verlag Wien

Kennaway, D. J.; Stamp, G. E. and Goble, F. C. (1992). 'Development of melatonin production in infants and the impact of prematurity', The Journal of Clinical Endocrinology \& Metabolism, 75(2): 367-369.

Liao, J.-M.; Zhou, X.; Zhang, Y. and Lu, H. (2012). 'MiR-1246: a new link of the p53 family with cancer and Down syndrome', Cell Cycle, 11(14): 2624-2630.

Liu, R.; Fu, A.; Hoffman, A. E.; Zheng, T. and Zhu, Y. (2013). 'Melatonin enhances DNA repair capacity possibly by affecting genes involved in DNA damage responsive pathways', BMC cell biology, 14(1): 1-8.

Lobo, V.; Patil, A.; Phatak, A. and Chandra, N. (2010).' Free radicals, antioxidants and functional foods: Impact on human health'. Pharmacogn Rev., 4(8): 118126.

Lott, I. T. (2012). 'Antioxidants in Down syndrome', Biochimica et Biophysica Acta (BBA)-Molecular Basis of Disease, 1822(5): 657-663.

Maharaj, D. S.; Glass, B. D. and Daya, S. (2007). 'Melatonin: new places in therapy', Bioscience reports, 27(6): 299-320.

Mrowicka, M.; Garncarek, P.; Miller, E.; Kedziora, J.; Smigielski, J.; Malinowska, K. and Mrowicki, J. (2009). '[Effect of melatonin on activity of superoxide dismutase (CuZn-SOD) in erythrocytes of patients during short-and long-term hypokinesis]', Wiadomosci lekarskie (Warsaw, Poland: 1960), 63(1): 3-9. 
Nandhakumar, S.; Parasuraman, S.; Shanmugam, M.; Rao, K. R.; Chand, P. and Bhat, B. V. (2011). 'Evaluation of DNA damage using single-cell gel electrophoresis (Comet Assay)', Journal of Pharmacology and Pharmacotherapeutics, 2(2): 107-111.

Nižetić, D. and Groet, J. (2012). 'Tumorigenesis in Down's syndrome: big lessons from a small chromosome', Nature Reviews Cancer, 12(10): 721-732.

Pandi-Perumal, S. R.; BaHammam, A. S.; Brown, G. M.; Spence, D. W.; Bharti, V. K.; Kaur, C.; Hardeland, R. and Cardinali, D. P. (2013). 'Melatonin antioxidative defense: therapeutical implications for aging and neurodegenerative processes', Neurotoxicity research, 23(3): 267-300.

Paravicini, T. M. and Touyz, R. M. (2008). 'NADPH oxidases, reactive oxygen species, and hypertension clinical implications and therapeutic possibilities', Diabetes care, 31(Supplement 2): S170S180.

Patel, A.; Rees, S. D.; Kelly, M. A.; Bain, S. C.; Barnett, A. H.; Prasher, A.; Arshad, H. and Prasher, V. P. (2014). 'Genetic variants conferring susceptibility to Alzheimer's disease in the general population; do they also predispose to dementia in Down's syndrome', BMC research notes, 7(1): 1-6.

Perluigi, M. and Butterfield, D. A. (2011). 'Oxidative stress and Down syndrome: a route toward Alzheimer-like dementia', Current gerontology and geriatrics research, 2012: 1-10.

Poeggeler, B.; Thuermann, S.; Dose, A.; Schoenke, M.; Burkhardt, S. and Hardeland, R. (2002). 'Melatonin's unique radical scavenging properties-roles of its functional substituents as revealed by a comparison with its structural analogs', Journal of pineal research, 33(1): 20-30.

Polimeni, G.; Esposito, E.; Bevelacqua, V.; Guarneri, C. and Cuzzocrea, S. (2014). 'Role of melatonin supplementation in neurodegenerative disorders', Front Biosci (Landmark Ed),1 (19): 429-446.

Reiter, R. J.; Tan, D.-X.; Tamura, H.; Cruz, M. H. C. and Fuentes-Broto, L. (2014). 'Clinical relevance of melatonin in ovarian and placental physiology: a review', Gynecological Endocrinology, 30(2): 83-89.

Robbiano, L.; Baroni, D.; Carrozzino, R.; Mereto, E. and Brambilla, G. (2004). 'DNA damage and micronuclei induced in rat and human kidney cells by six chemicals carcinogenic to the rat kidney', Toxicology, 204(2): 187-195.

Sliwinski, T.; Rozej, W.; Morawiec-Bajda, A.; Morawiec, Z.; Reiter, R. and Blasiak, J. (2007). 'Protective action of melatonin against oxidative DNA damagechemical inactivation versus base-excision repair', Mutation Research/Genetic Toxicology and Environmental Mutagenesis, 634(1): 220-227.

Sofic, E.; Rimpapa, Z.; Kundurovic, Z.; Sapcanin, A.; Tahirovic, I.; Rustembegovic, A. and Cao, G. (2005). 'Antioxidant capacity of the neurohormone melatonin', Journal of neural transmission, 112(3): 349-358.

Srinivasan, V.; Pandi-Perumal, S.; Maestroni, G.; Esquifino, A.; Hardeland, R. and Cardinali, D. (2005).
'Role of melatonin in neurodegenerative diseases', Neurotoxicity Research, 7(4): 293-318.

Subramaniam, P.; Girish Babu, K. and Mohan Das, L. (2014). 'Assessment of salivary total antioxidant levels and oral health status in children with Down syndrome', Special Care in Dentistry, 34(4): 193-200.

Sulthana, S. M.; Kumar, S. N.; Sridhar, M.; Bhat, B. V. and Rao, K. R. (2012). 'Levels of non enzymatic antioxidants in Down syndrome', The Indian Journal of Pediatrics, 79(11): 1473-1476.

Tan, X.; Guo, X. and Liu, H. (2013). 'Melatonin attenuates hippocampal neuron apoptosis and oxidative stress during chronic intermittent hypoxia via upregulating B-cell lymphoma-2 and down-regulating B-cell lymphoma-2-associated X protein', Saudi medical journal, 34(7): 701-708.

Uberos, J.; Romero, J.; Molina-Carballo, A. and Munoz-Hoyos, A. (2010). 'Melatonin and elimination of kynurenines in children with Down's syndrome', Journal of Pediatric Endocrinology and Metabolism, 23(3): 277-282.

Young, K. J. and Bennett, J. P. (2010). 'The mitochondrial secret (ase) of Alzheimer's disease', Journal of Alzheimer's Disease, 20(S2): 381-400.

Zana, M.; Janka, Z. and Kálmán, J. (2007). 'Oxidative stress: a bridge between Down's syndrome and Alzheimer's disease', Neurobiology of aging, 28(5): 648676.

Zhang, L.; Meng, K.; Jiang, X.; Liu, C.; Pao, A.; Belichenko, P. V.; Kleschevnikov, A. M.; Josselyn, S.; Liang, P. and Ye, P. (2013). 'Human chromosome 21 orthologous region on mouse chromosome 17 is a major determinant for Down syndrome-related developmental cognitive deficits', Human molecular genetics, 1;23(3): 578-89

Zhang, Y.; Liao, J. M.; Zeng, S. X. and Lu, H. (2011). 'p53 downregulates Down syndrome-associated DYRK1A through miR.1246', EMBO reports, 12(8): 811 817.

Zhou, J.; Zhang, S.; Zhao, X. and Wei, T. (2008). 'Melatonin impairs NADPH oxidase assembly and decreases superoxide anion production in microglia exposed to amyloid- $\beta 1-42$ ', Journal of pineal research, 45(2): 157-165.

Žitňanová, I.; Korytár, P.; Sobotová, H.; Šustrová, M.; Pueschel, S. and Duračková, Z. (2006). 'Markers of oxidative stress in children with Down syndrome', Clinical Chemical Laboratory Medicine, 44(3): 306-310. 